\title{
ANTERIOR COMMUNICATING ARTERY: A CADAVERIC STUDY
}

\section{Dhanalakshmi V ${ }^{1}$, Satish Kumar S *2, Suresh Kumar T ${ }^{3}$, Arun kumar K ${ }^{4}$.}

${ }^{1}$ Associate Professor, Department of Anatomy, Govt. Thoothukudi Medical College, Thoothukudi, Tamilnadu, India.

${ }^{{ }^{*}}$ Associate Professor, Department of Anatomy, Govt. Dharmapuri Medical College, Dharmapuri, Tamilnadu, India.

${ }^{3}$ Associate Professor, Department of Anatomy, Govt. Vellore Medical College, Vellore, Tamilnadu, India.

${ }^{4}$ Associate Professor, Department of Anatomy, Dhanalakshmi Srinivasan Medical College, Perambalur, Tamilnadu, India.

\section{ABSTRACT}

Background: Anterior communicating artery, a short trunk connecting the anterior cerebral arteries is important in stabilizing blood flow by acting as collateral channel. The present study was conducted to note the variations in anterior communicating artery which may be one of the reason for formation of aneurysm.

Materials and Methods: Anterior communicating artery was observed for its number, course, length and variations in 50 adult embalmed cadaveric brains after injecting with latex solution.

Results: Duplication of anterior communicating artery was found in 4 specimens (8\%) and it was absent in $2 \%$. The course of ACOA was oblique in $54.2 \%$ and transverse in $45.8 \%$. The length of ACoA was on an average of $2.82 \mathrm{~mm}$. The mean diameter of ACoA was $1.12 \mathrm{~mm}$. Fenestration of ACoA was seen in 4\%.Median artery of corpus callosum was found in 1 specimen.

Conclusion: Congenital anomalies of the intracranial arteries predispose to the formation of aneurysms due to an increased haemodynamic stress. Knowing the length, course and diameter of ACoA is important as it may guide radiologists in interpretation and neurosurgeons in microsurgical procedures.

KEY WORDS: Anterior communicating artery, Aneurysm, Duplication, Fenestration.

Address for Correspondence: Dr. Satish Kumar. S, Associate Professor, Department of Anatomy, Govt. Dharmapuri Medical College, Dharmapuri, Tamilnadu, India.

Mobile: 9677183832 \& 8144007472 E-Mail: dr.sat82@gmail.com

\begin{tabular}{|c|c|c|c|}
\hline Access this Article online & \multicolumn{3}{|c|}{ Journal Information } \\
\hline \multirow[t]{3}{*}{ Quick Response code } & \begin{tabular}{|c} 
International Journa \\
\begin{tabular}{|c|} 
ICV for 2016 \\
90.30
\end{tabular} \\
ISSN (E) 2321-4 \\
https://wn \\
Dol-Prefix: https
\end{tabular} & $\begin{array}{l}\text { Anatomy and Res } \\
\text { ISSN (P) 2321-8967 } \\
\text { hr.org/ijar.htm } \\
\text { doi.org/10.16965/ijar }\end{array}$ & $(\mathrm{cc}) \overline{\mathrm{BY}-\mathrm{ML}-\mathrm{BA}}$ \\
\hline & \multicolumn{3}{|c|}{ Article Information } \\
\hline & $\begin{array}{l}\text { Received: } 26 \text { Dec } 2018 \\
\text { Peer Review: } 26 \text { Dec } 2018 \\
\text { Revised: None }\end{array}$ & \multicolumn{2}{|c|}{$\begin{array}{l}\text { Accepted: } 12 \text { Feb } 2019 \\
\text { Published (O): } 05 \text { Mar } 2019\end{array}$} \\
\hline
\end{tabular}

\section{INTRODUCTION}

Variations are inherent part of human anatomy. Interesting variations in the origin and course of arteries have long received the attention of anatomists and surgeons. Anterior communicating artery which is an important artery of circle of Willis connects the two anterior cerebral arteries across the commencement of the longitudinal fissure.

The anterior communicating artery is significant as it gives off numerous anteromedial central branches along with anterior cerebral arteries and supply the optic chiasma, lamina terminalis, hypothalamus, para-olfactory areas, anterior 
columns of the fornix and the cingulate gyrus [1]. Hence the study of the vascular anatomy of anterior communicating artery gains much importance.

Aneurysms of the anterior communicating artery are the most common circle of Willis aneurysm[1]. Aneurysm arising from anterior communicating artery produce visual field defects, endocrine dysfunction and localized frontal headache[2].

Variations of anterior communicating artery like number, diameter or course become a matter of great concern to radiologists and neurosurgeons.

\section{MATERIALS AND METHODS}

The study was conducted in 50 adult embalmed human cadaveric brains in the Institute of Anatomy, Madras Medical College, Chennai. After removing the brain following routine dissection method, latex solution was injected into the internal carotid artery to clearly visualize the arteries. Anterior communicating artery was observed for its number, course, diameter, length and for any variations like fenestrations. Measurements were taken with digital Vernier caliper and photographed.

\section{RESULTS}

On observing the anterior communicating artery, duplication was found in 4 specimens $(8 \%)$ [Fig.1] and was absent in $2 \%$. Median artery of corpus callosum was found in one specimen (2\%)[Fig.2]. The course of ACOA was oblique in $54.2 \%$ and transverse in $45.8 \%$. The length of ACoA was on an average of $2.82 \mathrm{~mm}$ with a range of $1 \mathrm{~mm}$ to $6 \mathrm{~mm}$. The mean diameter of ACoA was $1.12 \mathrm{~mm}$ with the range of $0.74 \mathrm{~mm}$ to $2.1 \mathrm{~mm}$. Fenestration of ACoA was seen in 4\% [Fig.3].

Fig. 1: Duplicated ACoA.

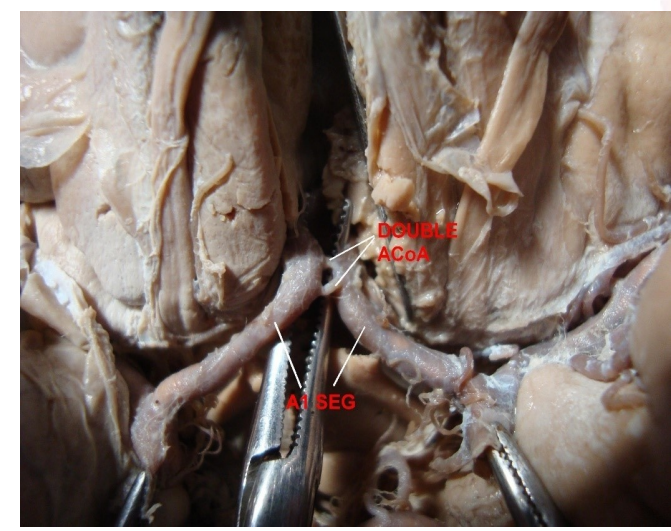

Fig. 2: Median artery of corpus callosum.

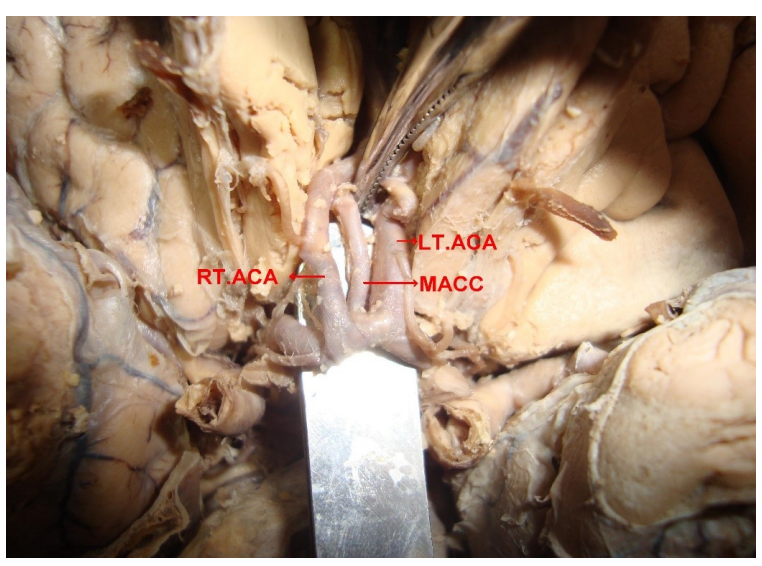

Fig. 3: Fenestrated ACoA.

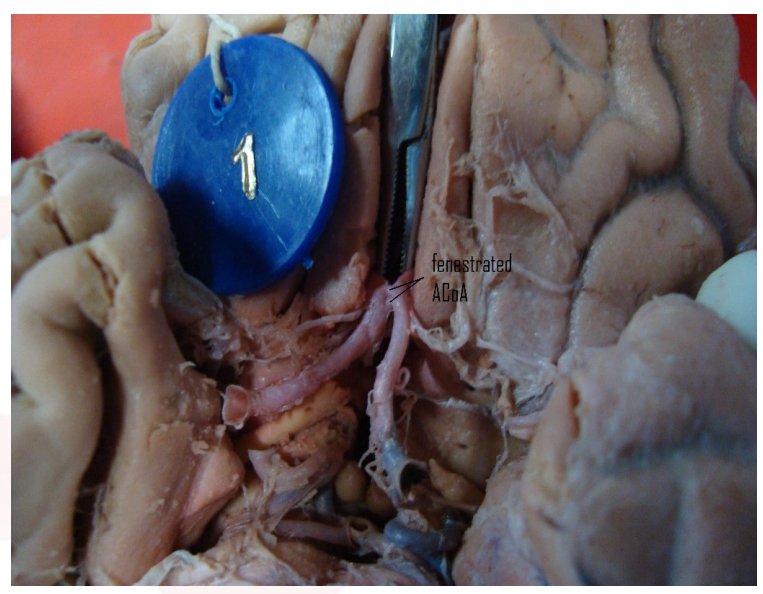

\section{DISCUSSION}

Congenital anomalies of the intracranial arteries predispose to the formation of saccular aneurysms due to an increased haemodynamic stress. Anterior communicating artery aneurysms were the most complex aneurysms of the anterior circulation due to the angio architecture and flow dynamics of the ACoA region, frequent anatomical variations, deep interhemispheric location, and danger of severing the perforators with ensuing neurologic deficits [3].

Anterior communicating artery aneurysm is the most common form of intracranial aneurysm, accounting for $25-38 \%$ of total cerebral aneurysm cases[4]. Multiple aneurysms of ACoA though rare has also been reported[5].

Patients with ruptured aneurysms of the anterior communicating artery are associated with damage to deep, medial frontal areas such as septal nuclei and present with amnestic syndrome[2].

The haemodynamics of the circle is influenced by variations in the caliber of communicating 
arteries of circulus arteriosus. Although a complete circular channel almost always exists, one vessel is usually sufficiently narrowed to reduce its role as a collateral route and the circle is rarely functionally complete. Cerebral and communicating arteries individually may all be absent, variably hypoplastic, double or even triple[1].

$A$ basic understanding of the embryologic development of the ACoA region allows us to anticipate its most common congenital anomalies. By 40 days (16 to $18 \mathrm{~mm}$ stage), the stem of the ACA elongates medially towards its counterpart. At this stage, a midline cluster of plexiform anastomoses begins to form between the adjacent and elongating ACAs. At 44 days (20 to $24 \mathrm{~mm}$ stage), the channels of the midline cluster of plexiform anastomoses coalesce and form one or more ACoAs. The coalescing channels of the midline cluster of plexiform anastomoses give rise to a median ACA that originates from the ACoA[6].

Hence the ACoA may be single, double, fenestrated or plexiform. Anterior communicating artery is more often double in 7 to 9 percent or even triple, and can be absent when there was fusion between the two anterior cerebrals[7]. In $21.4 \%$ patients with aneurysms of the anterior communicating artery, vascular anomalies in the vicinity of the ACOA were reported[8]. Duplication of ACoA can have incidence upto 14\%[9]. Triple ACoA was also reported[10].

Fenestration has been found to be the most common ACoA variation raising concern as this has been shown to compromise collateral flow and predispose to aneurysm formation[9]. Fenestration of the ACOA was reported in 12 out of 227 on 3D rotational angiography, 10 (83\%) were associated with 1 or more aneurysms of the ACoA[11]. Plexiform ACoA was reported in $0.4 \%[12]$. Double fenestration of the anterior communicating artery (ACoA) complex associated with an aneurysm was also reported[13]. Knowing the length, course and diameter of ACoA is important as it may guide radiologists in interpretation and neurosurgeons while doing microsurgery. The length of ACOA is usually between 2 and $3 \mathrm{~mm}$ but may vary from 0.3 to $7 \mathrm{~mm}[14]$. The diameter of ACoA was $1.5 \mathrm{~mm}$ (range $0.2 \mathrm{~mm}$ to $3.4 \mathrm{~mm}$ ), specified by Richard
Winn[15].

ACoA may not be oriented in a strictly transverse plane. It can be oriented in an oblique or anteroposterior plane, if one ACA passes between the hemispheres behind the other, as occurs in $80 \%$ of brains. It may be curved, kinked or tortuous rather than straight[14].

Female subjects have a higher incidence of variations in the anterior communicating artery complex. Neurosurgeons should be more alert while operating females, as they have a higher frequency of anatomical abnormalities in the ACoA complex[16].

\section{CONCLUSION}

Neurosurgeons treating aneurysms should anticipate variations and this comprehensive study of the course, length, diameter, and variations of anterior communicating artery will prove to be useful to the neurosurgeons who plan for endovascular surgeries, anastomosing surgeries and also for radiologists interpreting various imaging of anterior communicating artery.

\section{ABBREVIATIONS}

ACoA - Anterior communicating artery

ACA - Anterior cerebral artery

\section{ACKNOWLEDGEMENTS}

We would like to extend our sincere thanks to DR.Christilda Felicia Jebakani, former Director and Professor, Institute of Anatomy, Madras Medical College, Chennai for her valuable guidance and persistent support for this study.

\section{Conflicts of Interests: None}

\section{REFERENCES}

[1]. Susan standring. Gray's Anatomy, $40^{\text {th }}$ edition, Elsevier, Churchill Livingstone.2008:252.

[2]. Walter G. Bradley, Robert B. Daroff, Gerald M. Fenichel, Joseph Jankovic. Neurology in clinical practice. $5^{\text {th }}$ edition, volume 2,Butterworth Heinmann Elsevier, USA 2008;1243-44.

[3]. Karazincir S, Ada E, Sarsilmaz A, Yalçin O, Vidinli B, Sahin E. Frequency of vascular variations and anomalies accompanying intracranial aneurysms. Tani Girisim Radyol 2004 Jun;10(2):103-9.

[4]. Jung Hyun Park, Sang Keun Park, Tae Hong Kim, Jun Jae Shin, Hyung Shik Shin, and Yong Soon Hwang, Anterior Communicating Artery Aneurysm Related to Visual Symptoms.J Korean Neurosurg Soc. 2009 Sep; 46(3): 232-238. 
[5]. Inci S, Ozgen T Multiple aneurysms of the anterior communicating artery: radiological and surgical difficulties.JNeurosurg. 2005 Mar;102(3):495-502.

[6]. Randy Jinkins. J. Atlas of Neuroradiologic Embryology, Anatomy and Variants. Lippincott Williams \& Wilkins,2000, p- 25, 319-321,327.

[7]. Henry Hollinshead W (1968) Anatomy for Surgeons: vol 1, The Head and Neck, 2nd edition 196842-46, 57-60.

[8]. Ogawa A, Suzuki M, Sakurai Y, Yoshimoto T. Vascular anomalies associated with aneurysms of the anterior communicating artery: microsurgical observations.JNeurosurg. 1990 May;72(5):706-9.

[9]. Saidi H, Kitunguu PK, Ogeng'O JA. Variant anatomy of the anterior cerebral artery in adult brains. Afr J Neurol Sci 2008;27(1):97-105

[10]. Lee KC, Rhee YK. Microsurgical Anatomy of the Proximal Anterior Cerebral Artery and Anterior Communicating Artery. J Korean Neurosurg Soc. Mar 1981; 10(1):17-26.

[11]. A.N. de Gast, W.J. van Rooij and M. Sluzewski. Fenestrations of the Anterior Communicating Artery: Incidence on 3D Angiography and Relationship to Aneurysms, American Journal of Neuroradiology February 2008;29(2):296-298.

[12]. Kapoor K, Singh B, Dewan LI. Variations in the configuration of the circle of Willis, Jun 2008; 83(2):96106.
[13]. De Oliveira JG, du Mesnil de Rochemont R, Beck J, Hermann E, Gerlach R, Raabe A, Seifert V. A rare anomaly of the anterior communicating artery complex hidden by a large broad-neck aneurysm and disclosed by three-dimensional rotational angiography. ActaNeurochir (Wien). 2008 Mar;150(3):279-84.

[14]. Ronald A. Bergman, Adel K. Ann, RyosukeMiyauchi. Illustrated Encyclopedia of Human Anatomic Variation: Opus II: Cardiovascular system: Arteries: Head, Neck and Thorax-Anterior Communicating Artery 1995.

[15]. Richard Winn .H Youmans Neurological Surgery, vol 2, $5^{\text {th }}$ edition, Saunders, 1973, p - $1923-1947$.

[16]. Roger M. Krzyzÿewski · Krzysztof A. Tomaszewski • Micha ${ }^{3}$ Kochana.Ma ${ }^{3}$ gorzataKopec. Wies ${ }^{3}$ awaKlimek Piotrowska. Jerzy A. Walocha. Anatomical variations of the anterior communicating artery complex: gender relationship SurgRadiolAnat 2015;37:81-86.

How to cite this article:

Dhanalakshmi V, Satish Kumar S, Suresh Kumar T, Arun kumar K. ANTERIOR COMMUNICATING ARTERY: A CADAVERIC STUDY. Int J Anat Res 2019;7(1.3):6261-6264. DOI: 10.16965/ijar.2018.453 